ORIGINAL ARTICLE

\title{
Spectrum of lymph node pathology in adult onset Still's disease; analysis of 12 patients with one follow up biopsy
}

\author{
Y K Jeon, J H Paik, S-S Park, S O Park, Y A Kim, J E Kim, Y W Song, C W Kim
}

J Clin Pathol 2004;57:1052-1056. doi: 10.1136/jcp.2004.018010

\begin{abstract}
See end of article for authors' affiliations

Correspondence to:

Dr C W Kim, Department of Pathology, Seoul

National University

College of Medicine, 28

Yongon-dong, Chongno-

gu, Seoul, 110-799,

Korea; cwkim@plaza.snu. ac.kr
\end{abstract}

Accepted for publication 1 May 2004

\begin{abstract}
Background: Adult onset Still's disease (AOSD) is a rare systemic inflammatory disorder of unknown aetiology, frequently accompanying multiple lymphadenopathy. It often mimics malignant lymphoma, and immunohistochemical and molecular studies are needed for definite diagnosis.

Aims: To aid in diagnosis and understand the pathogenesis of the disease by clarifying lymph node (LN) pathology in AOSD.

Methods: Thirteen biopsies (one follow up biopsy) and medical records of 12 patients were reviewed. Immunohistochemistry, polymerase chain reaction for T cell receptor $\gamma$ chain (TCR $\gamma$ ) and immunoglobulin heavy chain gene rearrangement, and Epstein-Barr virus in situ hybridisation were performed.

Results: Histologically, LN lesions were classified into four patterns. The most common (six biopsies) showed paracortical hyperplasia, with prominent vascular proliferation, scattered large B/T immunoblasts, and infiltration by reactive lymphocytes and inflammatory cells. In the second pattern (two biopsies), paracortical hyperplasia was accompanied by massive sinus histiocytosis and S-100 positive histiocyte aggregates. The third pattern (three patients) showed an exuberant immunoblastic reaction, in the form of patchy/diffuse infiltration of large $T$ immunoblasts with high mitotic activity, although clonal rearrangement of the TCR $\gamma$ gene was not detected. The fourth pattern showed distinct follicular hyperplasia (two cases). One patient with a follow up biopsy showed a pattern change from pronounced follicular hyperplasia to atypical paracortical hyperplasia.

Conclusions: AOSD LN lesions show a dynamic histological spectrum, including atypical paracortical hyperplasia, burnt out histiocytic reaction, exuberant immunoblastic reaction, and follicular hyperplasia. During the course of disease, $L N$ reactivity changes and mixed B and T cells are involved in the pathogenesis.
\end{abstract}

S till's disease, an acute febrile form of juvenile rheumatoid arthritis, is a systemic inflammatory disorder of unknown aetiology, which rarely occurs in adults. Adult onset Still's disease (AOSD) is characterised by spiking fever, evanescent rash, arthritis, arthralgia, and the involvement of various organs. About $5 \%$ of patients with fever of unknown origin have AOSD. ${ }^{1}$ Despite the constellation of characteristic clinical manifestations, the absence of specific serological and pathological findings often makes this disease difficult to diagnose. In addition, the clinical features show some overlap with other rheumatological or infectious diseases, and even malignancies. Therefore, it is very important to exclude the possibility of other diseases.

\section{"Despite the constellation of characteristic clinical mani- festations, the absence of specific serological and pathological findings often makes this disease difficult to diagnose"}

Multiple lymphadenopathy develops in approximately 44$90 \%$ of patients with AOSD. ${ }^{2}{ }^{3}$ Therefore, it is one of the most common rheumatological diseases that the pathologist encounters. In the past, the lymph node pathology of AOSD was often described as merely normal or non-diagnostic reactive hyperplasia, and the nature of the lymphadenopathy was overlooked. ${ }^{1245}$ Valente et al described the characteristic lymph node histology of AOSD as atypical paracortical hyperplasia, and recently some authors reported scattered cases leading to confusion with malignant $\mathrm{T}$ cell lymphoma. ${ }^{6-9}$

We analysed the lymph node pathology of 13 specimens from 12 patients who underwent biopsy to exclude the possibility of malignant lymphoma. Clinical findings of all patients met the criteria of AOSD, and none of them developed malignant lymphoma during the follow up period. Through the analysis of our series of patients with clinicopathological, immunohistochemical, and genetic features, we reveal that the lymphadenopathy of AOSD shows a wide dynamic spectrum of pathological features.

\section{MATERIALS AND METHODS}

\section{Patients}

Twelve patients with AOSD underwent lymph node biopsy from 1995 to 2003. Eleven patients met the criteria of Cush et al and one patient (patient 10) met those of Yamaguchi et al. ${ }^{310}$ Cush's criteria are as follows: (1) fever ( $\left.\geqslant 39^{\circ} \mathrm{C}\right) ;(2)$ arthralgia or arthritis; (3) rheumatoid factor (RF) titre, $<1 / 80$ and antinuclear antibody (ANA) titre, $<1 / 100$; and (4) any two of the following: leucocytosis $\left(\geqslant 15000\right.$ cells $\left./ \mathrm{mm}^{3}\right)$, juvenile rheumatoid arthritis, rash, serositis (pleuritis or pericarditis), or evidence of reticuloendothelial involvement (hepatomegaly, splenomegaly, or generalised lymphadenopathy). In the definition proposed by Yamaguchi et al, five or more criteria, including two or more major criteria, need to be met, and the diseases listed below need to be excluded. Major criteria: (1) fever $\left(\geqslant 39^{\circ} \mathrm{C}\right.$, for one week or more), (2) arthralgia (for two weeks or more), (3) typical rash, (4) leucocytosis $\left(\geqslant 10000\right.$ cells $/ \mathrm{mm}^{3}$ ) with $80 \%$ more of

Abbreviations: ANA, antinuclear antibodies; AOSD, adult onset Still's disease; EBER, Epstein-Barr virus encoded RNA; EBV, Epstein Barr virus; FITC, fluorescein isothiocyanate; lgH, immunoglobulin heavy chain; PCR, polymerase chain reaction; RF, rheumatoid factor; $\mathrm{TCR} \gamma$, $\mathrm{T}$ cell receptor $\gamma$ chain 
granulocytes. Minor criteria: (1) sore throat, (2) lymphadenopathy or splenomegaly, (3) liver dysfunction, (4) negative RF and negative ANA. Diseases that should be excluded: (1) infections (especially, sepsis and infectious mononucleosis), (2) malignancies (especially, malignant lymphoma), (3) rheumatic diseases (especially, polyarteritis nodosa and rheumatoid vasculitis with extra-articular features).

\section{Immunohistochemistry and EBV in situ hybridisation}

Immunohistochemical staining was carried out using conventional streptavidin-biotin-peroxidase methods (LSAB kit; Dako, Carpinteria, USA), according to the manufacture's protocol. The primary antibody used, the method of antigen retrieval, and dilution factors are as follows: CD3 (Dako, Glostrup, Denmark; microwave; 1/250 dilution), CD4 (Dinona, Seoul, Korea; microwave; $1 / 250$ dilution), CD5 (Novocastra, Newcastle, UK; microwave; 1/50 dilution), CD8 (Dinona; pressure cooker; 1/200 dilution), UCHL-1 (Dako; no antigen retrieval; $1 / 400$ dilution), CD20 (Dako; microwave; $1 / 250$ dilution), S-100 protein (Dako; no antigen retrieval; 1/500 dilution), CD2 1 (Dako; microwave; 1/50 dilution), Ki-1 (CD30; Dako; microwave; 1/40 dilution), CD68 (Dako; microwave; 1/70 dilution), Ki-67 (Dako; microwave; 1/250 dilution), CD10 (Novocastra; pressure cooker; 1/80 dilution), epithelial membrane antigen (Dako; no antigen retrieval; $1 /$ 200 dilution), bcl-2 (Dako; microwave; 1/50 dilution), bcl-6 (Santa Cruz, California, USA; pressure cooker; 1/150 dilution), $\kappa$ light chain (Dako; trypsin; $1 / 200$ dilution), and $\lambda$ light chain (Dako; microwave; 1/250 dilution).

In situ hybridisation for Epstein-Barr virus (EBV) encoded RNAs (EBERs) was performed to confirm the presence of EBV. The hybridisation solution containing fluorescein isothiocyanate (FITC) labelled EBV oligonucleotide probe (cocktails of EBER1 and EBER2, Dakopatts, Glostrup, Denmark), and the Dako in situ hybridisation detection kit (code number K046), including alkaline phosphatase conjugated rabbit $\mathrm{F}\left(\mathrm{ab}^{\prime}\right) 2$ anti-FITC and enzyme substrate (5bromo-4-chloro-3-indolylphosphate nitroblue tetrazolium), were used.

\section{PCR analysis for TCR $\gamma$ chain and IgH gene rearrangement}

DNA was extracted from formalin fixed, paraffin wax embedded tissues using a conventional method, and polymerase chain reaction (PCR) analysis for T cell receptor $\gamma$ chain (TCR $\gamma)$ and immunoglobulin heavy chain (IgH) gene rearrangement was carried out as described previously. ${ }^{11}$
Briefly, for TCR $\gamma$, multiplex PCR including five different primers for the $\mathrm{V}$ segment and three for the $\mathrm{J}$ segment and heteroduplex analysis were performed. Seminested PCR for IgH used two different primer pairs designated FR3A/LJH and FR3A/VLJH.

\section{RESULTS}

\section{Clinical features}

Table 1 summarises the major clinical and laboratory features of the 12 patients. Patient 1 was presented to us at the third attack, and the others presented at the first attack with insidious or abrupt onset. The lymph node biopsy was done within one to four months from the onset of disease. The follow up biopsy of patient 12 was performed one month later. Culture studies, serological tests, and examination for variable autoantibodies to exclude the possibility of other infectious or rheumatological diseases showed no specific findings. Bone marrow studies were also performed, except in patients 8 and 11 , and were interpreted as reactive marrows, frequently with granulocytic hyperplasia. In patient 7, a few haemophagocytic histiocytes were detected. Five patients (patients 2, 4, 5, 8, and 11) exhibited polyclonal hypergammopathy without an M-spike on serum and urine protein electrophoresis. The situation was complicated in patients 7 and 12 by neurological deficits of altered mentality and status epilepticus, respectively. Patient 10 suffered from combined thyrotoxicosis and adrenal insufficiency. The initial storm of attack subsided in all patients after steroids and non-steroidal anti-inflammatory drug treatment. All the patients were alive and doing well except for occasional complaints of mild arthralgia and transient rashes during the follow up period.

\section{Pathological features}

The lymph node lesions could be classified into four distinct patterns according to the histological and immunohistochemical findings. The most common pattern (so called atypical paracortical hyperplasia pattern), seen in six patients (patients 1 to 5, and follow up biopsy of patient 12), was characterised by paracortical hyperplasia with vascular proliferation and mixed cell infiltration. Only a few residual follicles were noted. The cellular infiltrates in the paracortical areas were composed of many small to medium sized lymphocytes, some plasma cells, variable numbers of atypical large immunoblasts, and a few eosinophils. Most of the small to medium sized lymphocytes having round to slightly irregular nuclei and scant cytoplasm were T cells expressing

Table 1 Summary of clinical and laboratory findings

\begin{tabular}{|c|c|c|c|c|c|c|c|c|c|c|c|c|c|c|c|}
\hline No. & Age/Sex & Fever & $\begin{array}{l}\text { Arthralgia/ } \\
\text { arthritis }\end{array}$ & Rash & LAP & $\mathrm{H} / \mathrm{S}$ & $\begin{array}{l}\text { WBC (\% of } \\
\text { granulocyte) } \dagger\end{array}$ & RF & ANA & $\begin{array}{l}\text { W ESR } \\
(\mathrm{mm} / \mathrm{hr})\end{array}$ & $\begin{array}{l}\text { Ferritin } \\
\text { (ng/ml) }\end{array}$ & $\begin{array}{l}\text { AST/ALT } \\
\text { (IU/I) }\end{array}$ & $\begin{array}{l}\text { LDH } \\
\text { (IU/I) }\end{array}$ & $\begin{array}{l}\mathrm{F} / \mathrm{U} \\
(\mathrm{Mo})\end{array}$ & $\begin{array}{l}\text { Type of } \\
\text { LAPब }\end{array}$ \\
\hline 1 & $37 / F$ & + & + , poly & + & + & $-1-$ & $16.60(82 \%)$ & - & $1 / 40^{*}$ & 12.6 & 18440 & $40 / 13$ & 846 & 98 & 1 \\
\hline 2 & $32 / F$ & + & + , poly & + & + & $-/+$ & $16.05(83 \%)$ & - & - & 103 & 1630 & $176 / 63$ & 362 & 28 & I \\
\hline 3 & $19 / \mathrm{F}$ & + & + , poly & + & + & $+/+$ & $16.11(85 \%)$ & - & - & 53 & 222 & $31 / 10$ & 549 & 37 & i \\
\hline 4 & $24 / F$ & + & + , poly & + & + & $-1-$ & $17.29(78 \%)$ & - & - & 131 & 109 & $53 / 59$ & 690 & 26 & I \\
\hline 5 & $40 / F$ & + & + , oligo & + & + & $-/+$ & $32.20(93 \%)$ & $1 / 20^{*}$ & - & 40 & 15500 & $1605 / 563$ & 282 & 6 & I \\
\hline 6 & $39 / F$ & + & + , poly & + & + & $+/+$ & $24.40(84 \%)$ & - & $1 / 40^{*}$ & 37 & 779 & NA & NA & 69 & ॥ \\
\hline 7 & $21 / M$ & + & +, oligo & + & + & $+/+$ & $18.10(90 \%)$ & - & - & 55 & 21700 & $117 / 102$ & 662 & 5 & $\|$ \\
\hline 8 & $18 / \mathrm{F}$ & + & + , poly & + & + & $-1-$ & $19.40(80 \%)$ & - & - & 63 & 2980 & $142 / 226$ & NA & 96 & III \\
\hline 9 & $29 / M$ & + & +, oligo & + & + & $+/+$ & 21.40 (94\%) & - & - & 76 & 31714 & $100 / 63$ & 652 & 60 & III \\
\hline 10 & $28 / F$ & + & - & + & + & $+1-$ & $18.70(87 \%)$ & - & - & 85 & 1000 & $218 / 101$ & 1294 & 28 & III \\
\hline 11 & $26 / F$ & + & + , poly & + & + & $-1-$ & $15.51(80 \%)$ & - & - & 132 & 7870 & $30 / 13$ & 637 & 16 & IV \\
\hline 12 & $15 / M$ & + & + , poly & + & + & $+/+$ & $27.82(86 \%)$ & - & - & 136 & 23500 & $101 / 11$ & 362 & 5 & IV to I \\
\hline
\end{tabular}

ALT, alanine aminotransferase; ANA, antinuclear antibody; AST, aspartate aminotransferase; F/U, follow up; H/S, hepatomegaly/splenomegaly; LAP, multiple lymphadenopathy; LDH, lactate dehydrogenase; Mo, months; NA, not available; No., patient number; oligo, oilgoarticular (2 to 4 joints affected); poly, polyarticular (5 or more joints affected); RF, rheumatoid factor; WBC, white blood cell count; W ESR, Westergren erythrocyte sedimentation rate. Westergren ESR: normal range, 0-20 mm/hr; ferritin: normal range, 10-300 ng/ml; AST/ALT: normal range, 0-40 IU/litre; LDH: normal range, 100-225 IU/ litre.

*Positive at the dilution factor shown. $\mathrm{WWBC}$ in units of $\times 10^{9}$ cells/litre (normal range, 4-10 $\times 10^{9}$ cells/litre). ๆType of LAP, type of lymphadenopathy; I, atypical paracortical hyperplasia pattern; II, burnt out histiocytic pattern; III, exuberant immunoblastic reaction pattern; IV, follicular hyperplasia pattern. 

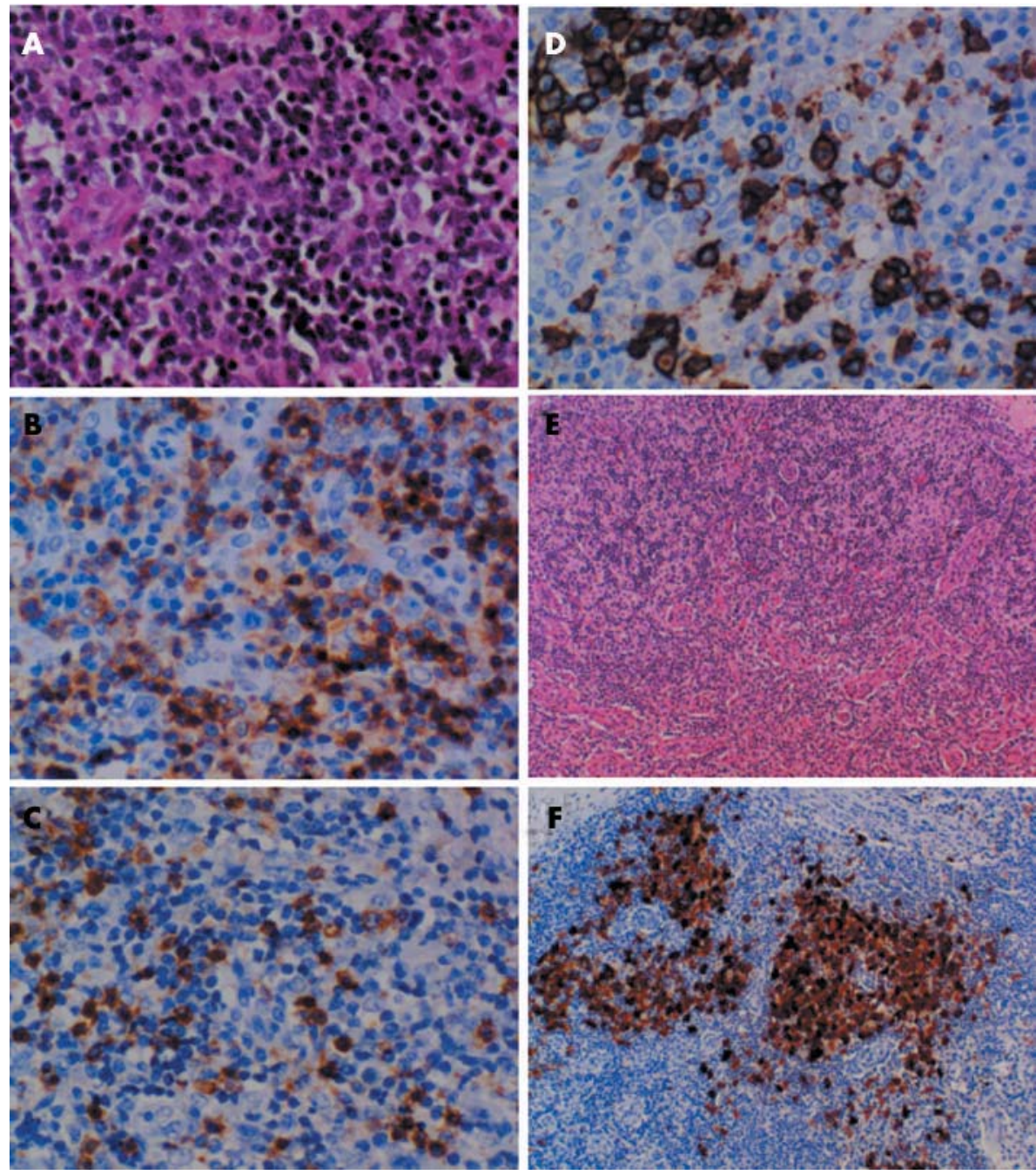

Figure 1 (A-D) Atypical paracortical hyperplasia pattern and (E, F) burnt out histiocytic pattern of lymphadenopathy in adult onset Still's disease (AOSD). (A) Widened paracortical area infiltrated by many small to medium sized lymphocytes, some large immunoblasts, plasma cells, and a few eosinophils. Haematoxylin and eosin (H\&E) stain; original magnification, $\times 400$. (B) CD4 expression in about three fifths of T cells. Immunoperoxidase stain; original magnification, $\times 400$. (C) CD8 expression in about two fifths of T cells. Immunoperoxidase stain; original magnification, $\times 400$. (D) CD20 expression in some of the large immunoblasts and a few small lymphocytes. Immunoperoxidase stain; original magnification, $\times 400$. (E)

Vascular transformation and sinus histiocytosis with mottled appearance. H\&E stain; original magnification, $\times 100$. (F) S- 100 protein expression in the aggregated histiocytes.

Immunoperoxidase stain; original magnification, $\times 200$.
CD3, CD5, and UCHL1. The ratio of CD4 to CD8 positive cells was about $3: 2$ (fig 1). The large immunoblastic cells with hyperchromatic nuclei, prominent nucleoli, and a moderate amount of cytoplasm were either B or $\mathrm{T}$ cells. These cells exhibited frequent mitoses and occasionally expressed Ki-1. Mild histiocytosis and focal areas of monocytoid B cell proliferation were noted.

The second pattern (so called burnt out histiocytic pattern) was characterised by exuberant paracortical hyperplasia with vascular proliferation and extensive sinus histiocytosis, and this pattern was seen in two patients (patients 6 and 7 ). There was no residual follicle in the representative section. The histiocytes were positive for CD68 and S-100 protein, and often aggregated in the cortex with a mottled appearance (fig 1). The third pattern (so called exuberant immunoblastic reaction pattern), seen in patients 8,9 , and 10 , was characterised by paracortical hyperplasia with massive infiltration of immunoblasts. This type was the most difficult pattern to differentiate from malignant lymphoma. In patient 9, patchy areas of lymph node were filled with large atypical immunoblasts, in a background of paracortical hyperplasia. These areas were, distinctly, composed of CD3+, UCHLl+, CD5-, and Ki-l- T immunoblasts, and the Ki-67 positive index was as high as $90 \%$ (fig 2). In patient 10, many scattered and clustered atypical Ki-l+ $\mathrm{T}$ immunoblasts diffusely infiltrated the entire lymph node (fig 2). The Ki67 positive index was as high as $70 \%$, and occasionally, apoptosis of individual cells was also noted. However, TCR $\gamma$ gene rearrangement analysis showed no clonal expansion of T cells (fig 3).

The last pattern (so called follicular hyperplasia pattern), seen in two cases (patient 11 and the initial biopsy of patient 12), was characterised by many follicles of variable size dispersed throughout the lymph node. Some of them showed hyperplastic germinal centres containing many tingible body macrophages and small $\mathrm{T}$ cells. Some exhibited vascular hyalinisation of the germinal centre and mantle/marginal zone widening, together with follicle lysis.

\section{EBER in situ hybridisation and PCR analysis for gene rearrangement}

EBER in situ hybridisation and a genetic study were performed in all patients, except for patient 8 . In patients 3 , 7, and 10, a few small lymphoid cells showed a positive signal for EBER. However, there were no EBER positive immunoblasts. EBER positive cells were not detected in the other patients. There was no evidence of clonal rearrangement of the TCR $\gamma$ gene and IgH gene in all cases examined, including two (patients 9 and 10) of the three patients with an exuberant immunoblastic reaction pattern (fig 3 ).

\section{DISCUSSION}

Although lymphadenopathy is a common manifestation and one of the diagnostic criteria of AOSD, there are only a few sporadic reports about lymph node pathology in AOSD. This might be because of the difficulty in recognising the 

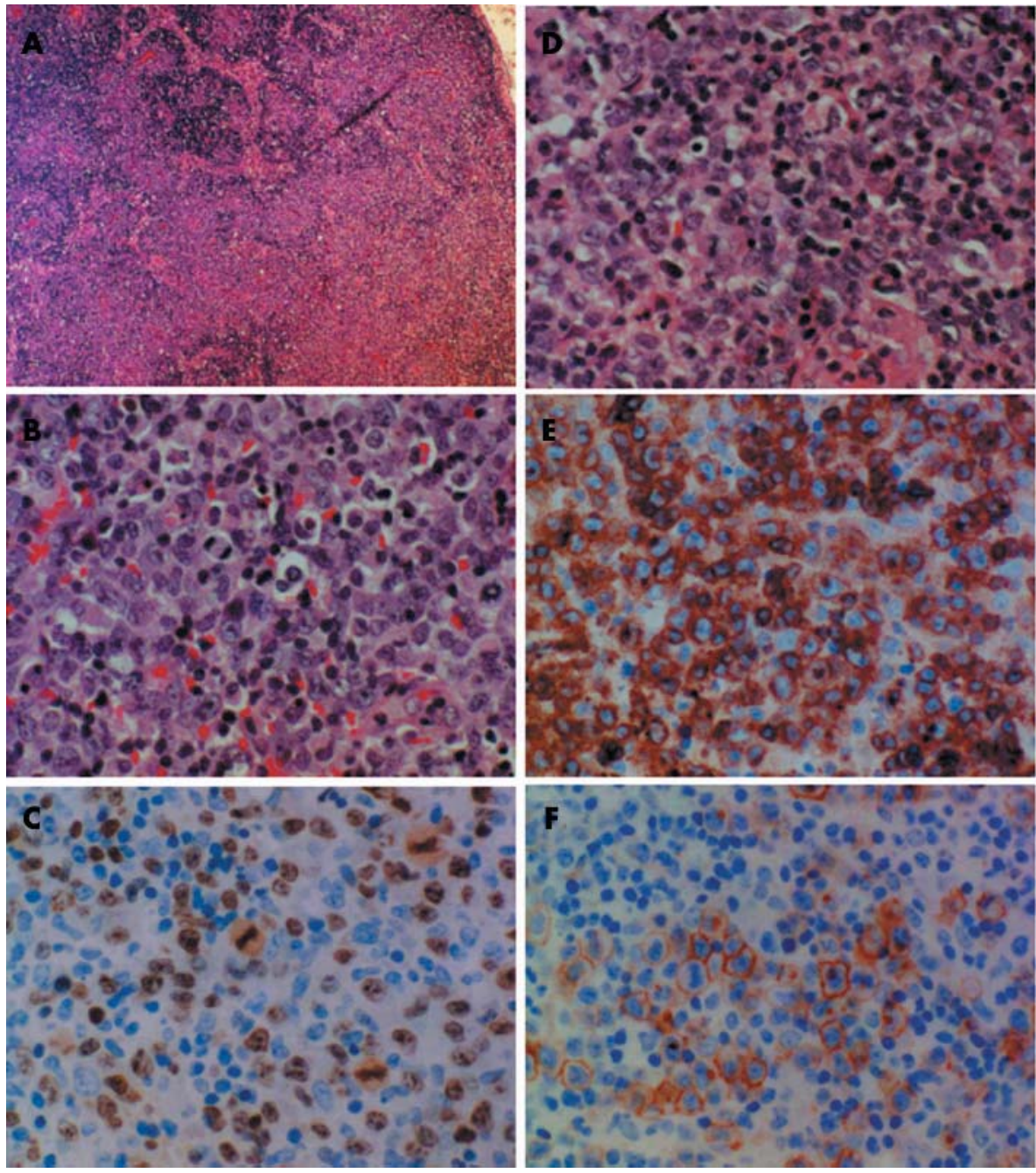

Figure 2 Exuberant immunoblastic pattern of lymphadenopathy in adult onset Still's disease seen in (A-C) patient 9 and (D-F) patient 10. (A) Patchy areas effaced by large atypical cells. Haematoxylin and eosin (H\&E) stain; original magnification, $\times 40$. (B) Large immunoblastic cells showing vesicular nuclei with prominent nucleoli, eosinophilic cyłoplasm, and frequent mitoses. H\&E stain; original magnification, $\times 400$. (C) High Ki-67 expression in immunoblastic cells. Immunoperoxidase stain; original magnification, $\times 400$. (D) Loosely aggregated large immunoblastic cells effacing the entire lymph node architecture. H\&E stain; original magnification, $\times 400$. (E) CD3 expression in most of the large immunoblastic cells. Immunoperoxidase stain; original magnification, $\times 400$. (F) $\mathrm{Ki}-1$ expression in many of the immunoblastic cells with a membranous and Golgi staining pattern.

Immunoperoxidase stain; original magnification, $\times 400$. pathological characteristics of biopsy specimens encountered only occasionally by pathologists. In addition, the clinical features of AOSD, which include fever, hepatosplenomegaly, skin rash, and polyclonal hypergammopathy, can mimic malignant lymphoma, so that understanding the lymph node pathology of AOSD is very important. AOSD lymphadenopathy has been described simply as "reactive hyperplasia, frequently with accompanying histiocytosis", "plasma cells and polymorphonuclear cell infiltrates with sign of reactive

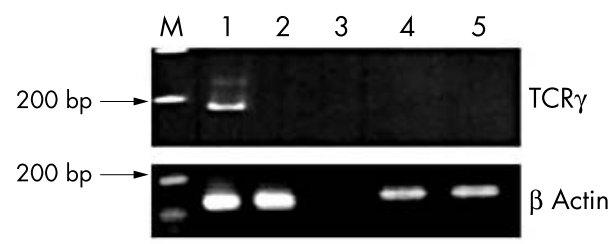

Figure 3 There was no evidence of clonal rearrangement of the T cell receptor $\gamma$ (TCR $\gamma$ ) gene by means of polymerase chain reaction (PCR) analysis in patients 9 and 10 who showed an exuberant T immunoblastic reaction (upper row). The lower row shows the results of PCR for $\beta$ actin. M, 100 bp ladder (DNA size marker); lane 1, Jurkat cell line (positive control cells for clonal rearrangement of the TCR $\gamma$ gene); lane 2, negative control (DNA extracted from patient without clonal rearrangement of the TCR $\gamma$ gene); lane 3, no DNA; lane 4, patient 9; lane 5, patient 10 . hyperplasia", "the follicular pattern of reactive hyperplasia", or "atypical paracortical hyperplasia". ${ }^{12612}$

Through a literature review and the analysis of our 12 cases, including the one with an additional follow up biopsy, we conclude that AOSD lymphadenopathy represents a wide spectrum of histopathological features showing dynamic changes. Basically, lymphadenopathy is characterised by paracortical hyperplasia with vascular proliferation. Other reports regarding AOSD as one of the causes of florid reactive follicular hyperplasia have also been found. ${ }^{12}{ }^{13}$ The follicular hyperplasia pattern was seen in two of our patients, and interestingly, the lymph node of patient 12 in our series showed a follicular hyperplasia pattern in the initial biopsy and atypical paracortical hyperplasia in the follow up biopsy. This might explain, in part, the various pathological descriptions of AOSD lymphadenopathy.

The widened paracortical area was infiltrated by variable numbers of atypical B and T immunoblasts, and the extent of the immunoblastic reaction determined the difficulty of the differential diagnosis from malignant lymphoma. In extreme cases, classified as exuberant immunoblastic reaction pattern, portions or entire areas of the lymph node were effaced by actively proliferating large $\mathrm{T}$ immunoblasts. In such cases, detailed evaluation of clinical and laboratory findings, and additional studies such as immunohistochemistry and TCR $\gamma$ gene rearrangement are mandatory. Unlike angioimmunoblastic T cell lymphoma, clear cell clusters, CD21 positive follicular dendritic cell proliferation in the extragerminal 
centre area, and EBER positive large B immunoblasts were not found in AOSD. In addition, in contrast to angioimmunoblastic $\mathrm{T}$ cell lymphoma, AOSD occurs mainly in young adults. And unlike peripheral T cell lymphoma, there was no distinct cellular atypism, and no clonal TCR $\gamma$ gene rearrangement. Mitotic activity was not increased in the small to medium sized $\mathrm{T}$ cells. Kojima et al also reported that the CD4 : CD8 positive cell ratio is about $3: 2$ and cytotoxic T cells are seen in AOSD. However, in nodal peripheral $\mathrm{T}$ cell lymphoma, most T cells are CD4 positive. ${ }^{8}$

"The lymph node of patient 12 in our series showed a follicular hyperplasia pattern in the initial biopsy and atypical paracortical hyperplasia in the follow up biopsy"

We could find no associations between the clinical features and lymph node patterns in AOSD. Although two of the three patients with an exuberant immunoblastic reaction were complicated by either respiratory distress or endocrinopathy, whether the degree of immunoblastic reaction might reflect the disease activity is not certain. Two patients with pronounced S-100 positive histiocytosis in the lymph node pathology showed raised serum ferritin values-from 70 to 100 times the normal value. One of them showed the feature of haemophagocytic syndrome on bone marrow examination. These findings are in accordance with the suggestion by Coffernils et al that the very high serum ferritin concentrations encountered in AOSD reflect the presence of histiocytic hyperactivity, which sometimes leads to a haemophagocytic syndrome. ${ }^{14}$

The pathogenesis of AOSD is unclear. An abnormal immune reaction to an infectious agent such as a virus has been suggested, although no such organism has been identified, and an imbalance of cytokines has also been proposed. ${ }^{15}$ Abnormal immune reactions can provoke various reactive lymphadenopathies and malignant lymphoma. In fact, there are several reports of AOSD accompanied by Kikuchi's disease, Castleman's disease, and malignant B cell lymphoma. ${ }^{15-19}$ A study done by Quaini et al showed that AOSD lymphadenopathy is a process involved by mixed B and $\mathrm{T}$ cells, ${ }^{7}$ and the dynamic change of lymph node pathology from follicular to paracortical hyperplasia in our study could also support their hypothesis. However, the facts

\section{Take home messages}

- The lymph nodes of adult onset Still's disease (AOSD) exhibit a wide spectrum of histopathological features, which can be classified into four patterns: atypical paracortical hyperplasia, burnt out histiocytic reaction, exuberant immunoblastic reaction, and follicular hyperplasia

- The histopathology of the lymph nodes can change dynamically during the course of disease

- Combining immunohistochemical and genetic studies with careful evaluation of clinical and laboratory findings would make diagnosis more accurate

- Understanding the nature of AOSD lymphadenopathy could also help to elucidate the pathogenesis of the disease that the major histological pattern of AOSD lymphadenopathy is atypical paracortical hyperplasia, and that the exuberant immunoblastic reaction frequently mimics malignant $\mathrm{T}$ cell lymphoma, suggest that the $\mathrm{T}$ cell mediated immune reaction may play an important role in the course of disease.

In conclusion, our report emphasises that the lymph nodes in AOSD exhibit a wide spectrum of pathohistological features, which can be classified into four patterns, and that the pathology can change dynamically during the course of disease. Although there was no definite association between lymph node pathology and clinical features, future studies may reveal such an association. Combining immunohistochemical and genetic studies with careful evaluation of clinical and laboratory findings would prevent the overdiagnosis and underdiagnosis of the lymph node specimen. Understanding the nature of AOSD lymphadenopathy could also help to elucidate the pathogenesis of the disease.

\section{Authors' affiliations}

Y K Jeon, J H Paik, S-S Park, S O Park, C W Kim, Department of Pathology and Cancer Research Institute, Tumour Immunity Medical Research Centre, Seoul National University College of Medicine, Seoul 110-799, Korea

Y A Kim, J E Kim, Department of Pathology, Seoul City Boramae Hospital, Seoul 156-707, Korea

Y W Song, Division of Rheumatology, Department of Internal Medicine, Seoul National University College of Medicine

\section{REFERENCES}

1 Bujak JS, Aptekar RG, Decker JL, et al. Juvenile rheumatoid arthritis presenting in the adult as fever of unknown origin. Medicine 1973;52:431-44.

2 Reginato AJ, Schumacher HR, Baker DG, et al. Adult onset Still's disease: experience in 23 patients and literature review with emphasis on organ failure. Semin Arthritis Rheum 987, 17:39-57.

3 Cush JJ, Medsger TA, Christy WC, et al. Adult-onset Still's disease-clinical course and outcome. Arthritis Rheum 1987;30:186-94.

4 Goldman JA, Beard MR, Casey HL. Acute febrile juvenile rheumatoid arthritis in adults: causes of polyarthritis and fever. South Med J 1980;73:555-63.

5 Kaplinsky N, Pras M, Frankl O. An adult form of juvenile rheumatoid arthritis. Arch Intern Med 1980;140:1073-4.

6 Valente RM, Banks PM, Conn DL. Characterization of lymph node histology in adult onset Still's disease. J Rheumatol 1989;16:349-54.

7 Quaini F, Manganelli P, Pileri S, et al. Immunohistologic characterization of lymph nodes in two cases of adult onset Still's disease. J Rheumatol 1991;18:1418-23.

8 Kojima M, Nakamura S, Miyawaki S, et al. Lymph node lesion in adult-onset Still's disease resembling peripheral T-cell lymphoma: a report of three cases. Int J Surg Pathol 2002;10:197-202.

9 Reichert LM, Keuning JJ, Beek M, et al. Lymph node histology simulating T-cell lymphoma in adult-onset Still's disease. Ann Hematol 1992;65:53-4.

10 Yamaguchi $M$, Ohta A, Tsunematsu T, et al. Preliminary criteria for classification of adult Still's disease. J Rheumatol 1992;19:424-30.

11 Trainor KJ, Brisco MJ, Wan JH, et al. Gene rearrangement in B- and Tlymphoproliferative disease detected by the polymerase chain reaction. Blood 1991;78:192-6.

12 Dorfman RF, Warnke R. Lymphadenopathy simulating the malignant lymphoma. Hum Pathol 1974;5:510-50.

13 Kojima M, Nakamura S, Shimizu K, et al. Florid reactive follicular hyperplasia in elderly patients. A clinicopathological study of 23 cases. Pathol Res Pract 1998;194:391-7.

14 Coffernils M, Soupart A, Pradier O, et al. Hyperferritinemia in adult onset Still's disease and the hemophagocytic syndrome. J Rheumatol 1992; 19:1425-7.

15 Ohta A, Matsumoto Y, Ohta T, et al. Still's disease associated with necrotizing lymphadenitis (Kikuchi's disease): report of 3 cases. J Rheumatol 1988;15:981-3.

16 Garazzi S, Grossin M, Kahr MF. Adult onset Still's disease and Kikuchi's disease. A new case. Rev Rhum Engl Ed 1997;64:352-3.

17 Lin SJ, Hsueh C, Chao HC. Localized hyaline vascular type of Castleman's disease mimicking adult-onset Still's disease. Clin Rheumatol 1999;18:485-7.

18 Trotta F, Dovigo L, Scapoli G, et al. Immunoblastic malignant lymphoma in adult onset Still's disease. J Rheumatol 1993;20:1788-92.

19 Sono H, Matsuo K, Miyazato H, et al. A case of adult onset Still's disease complicated by non-Hodgkin's lymphoma. Lupus 2000;9:468-70. 